4. Бодрийяр, Ж. Символический обмен и смерть / пер. с фр. С. Н. Зенкина. - 5-е изд. - Москва: Добросвет : Изд-во КДУ, 2000. - 387 с. - Текст : непосредственный.

5. Данилин, А. Г. Желание и «современность» : [лекция № 9]. - Текст : электронный // Нет наркотикам: информационно-публицистический ресурс. - Москва, 2001-.- URL: http://www.narkotiki.ru/ masterclass_5464.html (дата обращения: 23.03.2019).

6. Эткинд, А. Эрос невозможного. История психоанализа в России. - Москва : Медуза, 1993. - 464 с. Текст : непосредственный.

7. Stigmata [псевд.]. Откуда пришли готы / Молодёжная одежда «ГотикСтайл» : [интернет-магазин]. Москва, 2006- . - URL: http://gothicstyle.ru/articles_78.htm_(дата обращения: 23.03.2019).

8. Хиз, Дж. Бунт на продажу / Дж. Хиз, Э. Поттер. - Москва : Добрая книга, 2007. -456 с. - Текст : непосредственный.

9. Вайнштейн, О. Денди: мода, литература, стиль жизни. - Москва : Новое литературное обозрение, 2006. - 640 с. - Текст : непосредственный.

10. Тырышкина, Е. В. Декаданс - авангард - постмодернизм: трансформация эстетического дискурса. Текст : электронный // Поэзия авангарда. - URL: http://avantgarde.narod.ru/beitraege/ov/et_transformation.htm (дата обращения: 23.03.2019).

11. Данилин, А. Г. Наркотик массовой культуры : [лекция № 7, ч. 1] // Нет наркотикам: информационно-публицистический ресурс. - Москва, 2001-.- URL: http://www.narkotiki.ru/masterclass_5251.html (23.03.2019).

Evgenia A. Moskovkina, Ph. D. in Philology, Associate Professor Altai State Institute of Culture (Barnaul, Russia) evgenya.moskovkina@yandex.ru

\title{
POETICS OF DECADENCY IN ADVERTISING DISCOURSE
}

Abstract. Poetics of decadency is a program experience of aestheticization in the today's advertising/commercial practice. Inclusion of decadency wording into advertising discourse determined by the modern culture's want of "sharp expressiveness". Another reason of popularization of decadency in advertising is in the next pragmatic mindset - appellation to irrational, mystique, gothic signs and symbols provides a competitive advantage to a promotional message, helps to draw a buyer's attention. Aesthetic of decadency serves to attraction consumers fed up by false optimism of "hard sell" philosophy.

Keywords: a text, a symbol, decadency, advertising/commercial, a discourse, poetics, semiotics, aesthetics, sensibility, embodiment, a counterculture, a subculture, narcissism.

УДК 351.85(571.56):39(=512.1)

DOI: 10.32340/2414-9101-2019-3-9-14

С. В. Никифорова, кандидат культурологии

Северо-Восточный федеральный университет им. М. К. Аммосова (Якутск, Россия) nsv2107@mail.ru

Е. А. Дьячковская

Северо-Восточный федеральный университет им. М. К. Аммосова (Якутск, Россия) kachuuka@mail.ru

\section{ПОТЕНЦИАЛ КУЛЬТУРНОГО НАСЛЕДИЯ В ИДЕНТИФИКАЦИОННЫХ СТРАТЕГИЯХ РЕГИОНА}

Аннотация. Охарактеризована роль ряда объектов природного и культурного наследия, расположенных на территории современной Республики Саха (Якутия), в процессе становления национально-культурной идентичности представителей коренного населения региона - тюркского народа саха (самоназвание-«сахалар»). Рассмотрены теоретические основы механизма конвертации ценностно-смысловой составляющей памятников природы и наиболее 
значимых объектов культурного ландшафта территории в ресурс для построения культурноидентификационных стратегий региона.

Ключевые слова: национально-культурная идентификаџия этноса, идентификационные стратегии, российский регион, массовое сознание, культурное и природное наследие, культурная идентичность, культурные ценности, повседневная культура, традииионная (народная) культура, начионально-культурное самосознание, сочиокультурные практики, начиональные проекты, саха (якуты), Республика Саха (Якутия).

В рамках изучения проблем конструирования культурной идентичности индигенных народов Северо-Востока Российской Федерации (проблематика диссертационного исследования соавтора - Е. А. Дьячковской) проводится анализ эффективности национальных проектов и региональных программ по сохранению культурного и природного наследия. В сложившихся социокультурных практиках (в краеведении, истории и антропологии) культурное наследие принято рассматривать как законченную историческую данность, то есть нечто, веками сложившееся, требующее выявления, охраны, исследования, паспортизации и консервации. В сознании большинства носителей культуры наследие непременно должно быть освящено народным признанием, и желательно, чтобы было включено в Список материального (нематериального) наследия человечества, если не ЮНЕСКО, то хотя бы в региональный охранный реестр.

Настоящая статья позволит проанализировать, ранжировать и уточнить актуальные социокультурные практики в регионе, которые объединены идеями сохранения, реконструкции и актуализации культурного наследия. Культурное наследие трактуется так, как оно определено ЮНЕСКО в «Конвенции об охране всемирного культурного и природного наследия» (1972 г.). В первой и второй статьях названного документа приведены достаточно подробные и однозначные - что необходимо в практическом применении разными странами - толкования ключевых понятий «культурное наследие», «природное наследие». «Под “культурным наследием” понимаются: памятники: произведения архитектуры, монументальной скульптуры и живописи, элементы или структуры археологического характера, надписи, пещеры и группы элементов, которые имеют выдающуюся универсальную ценность с точки зрения истории, искусства или науки; ансамбли: группы изолированных или объединённых строений, архитектура, единство или связь с пейзажем которых представляют выдающуюся универсальную ценность с точки зрения истории, искусства или науки; достопримечательные места: произведения человека или совместные творения человека и природы, а также зоны, включая археологические достопримечательные места, представляющие выдающуюся универсальную ценность с точки зрения истории, эстетики, этнологии или антропологии. В настоящей Конвенции под “природным наследием" понимаются: природные памятники, созданные физическими и биологическими образованиями или группами таких образований, имеющие выдающуюся универсальную ценность с точки зрения эстетики или науки; геологические и физиографические образования и строго ограниченные зоны, представляющие ареал подвергающихся угрозе видов животных и растений, имеющих выдающуюся универсальную ценность с точки зрения науки или сохранения; природные достопримечательные места или строго ограниченные природные зоны, имеющие выдающуюся универсальную ценность с точки зрения науки, сохранения или природной красоты» [1].

В данном документе культурное и природное наследие признается, как совокупность ценностей, на которой строятся идентификационные стратегии любого региона. Например, таково значение наскальных рисунков Каповой пещеры для башкирского народа; металлопластика пермского звериного стиля для коми и пермяков или петроглифы Верхней Лены, в частности, фрагмент наскальной живописи - написанный охрой всадник со штандартом - в гербе Республики Саха (Якутия) для саха (якутов). Официальное описание герба: «в серебряном поле червлёный (красный) всадник со знаменем, имеющим три косицы; лазоревая (синяя, голубая) кайма» [2, с. 28]. Ни автор мамонтов и лошадей на Урале, ни автор верблюдов и всадника, написанного охрой 
на отвесной поверхности Ленской скалы, не имели ни малейшего отношения к народам и культурам, использующим их сегодня в качестве символов национального самосознания, брендов и маркеров культур указанных регионов. Но все названные выше образцы культурного наследия активно, если не сказать, определяющим образом участвуют в процессе региональной идентификации современных носителей культуры. Подобные образцы памятников культурного наследия одним фактом своего существования в качестве сакрального пространства или «места силы» определяют пространственные координаты жизни человека, то есть ложатся в основу его жизненных ощущений.

Идентификационные стратегии рассматриваются на данном этапе исследования (не совсем критично, но достаточно валидно): как «модели адаптации» [3, с. 124]; «комплекс механизмов и приемов, направленных на конструирование идентичности» [4, с. 51]; «приоритеты и иерархия ценностей» [5, с. 117]. Более того, поскольку в современных социокультурных практиках идентификационные стратегии используются как инструмент в ходе конструирования культурной идентичности, а также как выгодные политические тактики (брендинг, имидж региона, предвыборные обращения к архетипам массового сознания и т. д.), в предполагаемом исследовании они будут рассматриваться в качестве долгосрочных целей и направлений развития региона.

Сакральные пространства (места памяти, священные места, места памятников культурного/природного наследия) есть результат отбора культурной памяти - отклик на расширение семантического поля, наслоение различных по времени событий и значений. Это всегда результат срабатывания механизмов культурной памяти, когда образ места складывается из нанизывания коннотативных смыслов в разных стратах культурного пространства, по сути, он есть заявка на освоение культурного наследия. Процесс создания сакрального пространства выделен и описан А. М. Лидовым и назван им «иеротопизация» [6, с. 61], когда образ места отражает потребности региона, является визитной карточкой, брендом.

Любой план работы учреждения культуры (от плана сельского Дома культуры и досуга, до национальных проектов Российской Федерации), как и любой проект социокультурной направленности - независимо от масштаба и срока-неизбежно будет содержать посыл к иеротопии. Например, в сельском плане будет прописана строка ухода за бетонным памятником героям Гражданской или Великой Отечественной войн с копеечным бюджетом. В национальном проекте «Культура» с 2019 по 2024 год деятельность указанного направления обозначена как «утверждение инвестиционных паспортов усадеб», «реализация творческих проектов.., направленных на укрепление российской гражданской идентичности на основе духовно-нравственных и культурных ценностей народов РФ» и «создание памятных мест, связанных с военной историей» [7, c. 30], куда государством заложены миллиарды.

На протяжении последних десятилетий мы являемся свидетелями иеротопизации местности Ус Хатын (Три берёзы) в пригороде Якутска, когда каждый последующий руководитель региона вкладывается в этот проект, понимая его сакральный и долговременный характер, его значение в становлении национально-культурной идентичности современных саха. Этнокомплекс «Ус Хатын»- один из крупнейших проектов, по организации места проведения ежегодных ысыахов религиозных родовых молений Небу, Земле, Воде. Во время ысыаха совершались бескровные жертвоприношения, окропление кумысом - подношение верховным божествам, отпускали на волю жертвенное животное - «ытык» (лошадь белой масти), с тем, чтобы божества Айыы и дух Иччи приносили и в будущем богатство и удачу роду саха. После обряда кропления устраивали ритуальную трапезу, ритуальные игры - гадания, конные скачки и обрядовый круговой танец «осуохай». Принято обязательно выделять два ключевых круговых обряда: обряд кумысопития по кругу из одного чорона (резного деревянного кубка) и круговой танец «осуохай». Традиционно принято считать, что каждый участник танца заряжается энергией солнца. «Ысыах» был связан с идеей создания Вселенной и человека. Происхождение праздника проецируется на миф об Эллэе - «культурном герое», первопредке народа саха. Все культурные блага создаются руками Эллэя (он кузнец, горшечник, строитель, проповедник новой религии, связанной с культом Айыы)» 
[8, с. 508-509]. Центральные трибуны кумысопития, вмещают 15 тысяч мест. Здесь в 2012 году был установлен рекорд Гиннеса «Самый большой осуохай в мире», когда в 36 кругов встали 15293 человека в национальных костюмах.

Практически каждый наслег, каждый алаас - всякое место, где ступала нога человека - имеет свою культурную историю. Другое дело: хранит ли память? Проблема - в степени сохранности, насколько культивируемые на местном уровне мифы, культурная память работают на имидж, развитие, становление патриотических ценностей и качества жизни в культурах разных этносов. Например, саха, эвенки, эвены, татары и русские; субэтнос казаков и субкультура ямщиков в Олекминском улусе, имеющие единую топографическую основу: когда в одном месте сошлись хозяйственные, ритуальные, сакральные, религиозные культурные пласты представителей разных родов, этносов, субэтносов, конфессий и форм жизнедеятельности. Здесь более уместно понятие, введенное М. Фуко - «поликультурная гетеротопия» («перекресток культур»), отличительные признаки которой: «высокий индекс терпимости к иным традициям, наличие многообразных культурных традиций и атрибутов, соседствующих в одном пространстве; культурнонормативный либерализм» [9, с. 11]. Для культурного пространства Республики Саха (Якутия) наиболее характерны именно такие слоёные или синтезированные миксты, культурные перекрёстки, которые выше определены как поликультурная гетеротопия. Усложнение культурной памяти ведёт к изменению статуса места, что, в свою очередь, порождает более устойчивые и жизнеспособные культурные формы. В народном сознании образ культурного пространства представляет симбиоз сакрального и профанного, при этом сакральное имеет, как правило, более сложную архитектонику - исторически сложившуюся конструкцию тесно переплетённых различных страт (пластов): историческое, мифологическое, конфессиональное, мистическое, ритуальное и другие содержания уровней «страт» культурного пространства. В традиционной культуре саха (якутов) «священными объектами считались: перевалы; водоразделы; деревья; наскальные изображения; объекты природы необычного вида; места древних поселений; территории, отмеченные историкокультурными памятниками, ритуальной архитектурой, жертвенными знаками (кэрэх) ... Великие долины (Улуу сирдэр), ... могилы предков, шаманские захоронения» [10, с. 311]. То есть, изначально эти объекты культурного наследия не могут быть перенесены куда-либо, их удел«мягкая музеефикация» [11, с. 47], то есть изначально более затратная и менее прогнозируемая процедура иеротопизации.

В качестве второго примера практики идентификационных стратегий Республики Саха (Якутия) можно назвать социокультурные процессы, происходящие сегодня в с. Баяга Таттинского улуса, инициируемые сообществом народных мастеров по металлу (кузнецы) и бересте (берестой занимаются, как правило, женщины) под руководством Б. Ф. Неустроева - Мандар Ууса. На протяжении ряда лет идет работа по реконструкции Могол Урасы, культурологи (этнологи, антропологи, архитекторы, строители) имеют возможность наблюдать не столько процесс реконструкции объекта этнической архитектуры, сколько процесс иеротопизации создания сакрального пространства, в котором задействована национальная элита. Закономерно, что в современных условиях процесс реконструкции архитектурного строения подобного эпического размаха уже на уровне замысла становится памятником историко-культурного наследия на всем пространстве Северо-Востока Азии и выгружается в информационное поле: издание красочного альбома, выступления мастеров на телевидении и радио, освещение событий в прессе, организация семинаров и научно-практических конференций. Участники проекта понимают происходящее как миссию не только мастера Бориса Фёдоровича Неустроева - Мандар Уус, вдохновителя и идеолога, но ответственность всего поколения современных саха перед потомками, а с. Баяга уже сегодня воспринимается каждым, кому дорога родная культура, в качестве Мекки, со временем, при оптимальной логистике и правильном информационном освещении станет местом силы, культурной достопримечательностью. Секреты мастерства в кузнечестве и шитье, передаваемые не столько как технологии, но больше как сакральное знание многих поколений творцов (горшень, швей и кузнецов) создают мощный контент, перерас- 
тающий рамки аттрактивного образа территории. Баяга как место, претендующее на звание духовного центра, каковым оно, по сути, уже сложилось.

При таком понимании культурное наследие есть та ось, вокруг которой стратегии выстраиваются; та константа или универсальный ориентир, объективная статичность которого служит платформой для более общего варианта - культурной идентификации. В ходе исследования оснований для культурной идентификации мы опираемся на выделяемые В. М. Пивоевым семь аспектов культурной идентификации: «мифологическая самоидентификация, социально-ролевая самоидентификация, гендерная идентификация, этническая, профессиональная, возрастная и социально-престижная идентификации» [12, с. 170-171].

Механизмы реализации стратегий определяют специфику жизнедеятельности населения определённого региона: помимо ландшафта и климата, к ним относятся традиции, обыденные правила, сложившийся имидж, бренды, реклама, инструкции и циркуляры, социальные сети. Таким образом, мы отмечаем, что идентификационные стратегии органично (стихийно, постепенно включаясь в традицию либо директивно) реализуются в трёх стратах региональной культуры: в пространстве повседневности, в пространствах массовой (популярной) и традиционной культур, определяя и укореняя обыденное, массовое и национальное самосознание.

\section{Список литературы}

1. Конвенция об охране всемирного культурного и природного наследия: принята 16 нояб. 1972 г. Генеральной конференцией Организации Объединённых Наций по вопросам образования, науки и культуpы. - Текст : электронный // Организация Объединённых Наций : [сайт]. - URL: https://www.un.org/ru/documents/ decl_conv/conventions/heritage.shtml (дата обращения: 22.04.2019).

2. Официальные символы Республики Саха (Якутия) / [сост.: А. К. Акимов, К. И. Андреева, А. М. Матвеев ; авт. текстов: М. Ю. Медведев [и др.] ; подгот. Геральд. советом при Президенте Респ. Саха (Якутия)]. - Якутск : Бичик, 2006. - 219 с. - Текст : непосредственный.

3. Данилова, Е. Н. Идентификационные стратегии: российский выбор. - Текст : непосредственный // Социологические исследования. - 1995. - № 6. - С. 120-130.

4. Смирнов, А.В. Идентификационные стратегии повседневности: методологический аспект.Текст : непосредственный // Вестник Санкт-Петербургского университета. - 2008. - Сер. 6. - Вып. 3.C. $48-55$.

5. Шемякин, Я. Г. Феномен модернизации: цивилизационное измерение. Ст. 2. Ценности модернизации на Западе и в "незападном" мире: особенности восприятия и динамика эволюции идентификационных стратегий. - Текст : непосредственный // Общественные науки и современность. - 2016. - № 1. - С. 117128.

6. Лидов, А. М. Иеротопия: создание сакральных пространств как вид творчества и предмет исследования. - Текст : непосредственный // Государство, религия, церковь в России и за рубежом. - 2009.№ S2. - C. 60-72.

7. Национальные проекты: целевые показатели и основные результаты: на основе паспортов национальных проектов, утверждённых президиумом Совета при Президенте Российской Федерации по стратегическому развитию и национальных проектамм 24 декабря 2018 г. : [матер. по сост. на 7 февр. 2019 г.] Москва : [б. и.], 2019. - 110 с. : ил. - Текст : непосредственный.

8. Романова, Е. Н. Мистические представления и народный календарь. - Текст : непосредственный // Якутия, историко-культурный атлас. Природа. История. Этнография. Современность/ [науч. ред. В. Н. Иванов]. - Москва : Дизайн. Информация. Картография, 2007. - С. 500-509.

9. Баева, Л. В. Культурная гетеротопия: типология и признаки. - Текст : непосредственный // Ценности и смыслы. - 2017. - № 2. - С. 6-19.

10. Романова, Е. Н. Священные места Якутии: традиции и современность. - Текст : непосредственный // Образы евразийских пространств: пути, перекрёстки, святые места : матер. науч.-метод. семинара (Новосибирск, 4 мая 2012 г.). - Новосибирск : [б. и.], 2012. - С. 309-316.

11. Кимеева, Т. И., Глушкова, П. В., Родионов, С. Г. Музеефикация и актуализация объектов историко-культурного наследия в экомузее «Тазгол». - Текст : непосредственный / Т. И. Кимеева, П. В. Глушкова, С. Г. Родионов // Вестник Кемеровского государственного университета. - 2015. - № 3-1. - С. 46-51.

12. Пивоев, В. М. «Своё» и «чужое» в культуре народов Европейского Севера: проблемы идентифи- 
кации. - Текст : непосредственный // Мир культуры и культурология : альманах научно-образо-вательного культурологического общества России. - Санкт-Петербург : Изд-во РХГА, 2011. - С. 162-175.

Sargylana $V$. Nikiforova, Ph. D. in Cultural Studies, Associate Professor Ammosov North-Eastern Federal University (Yakutsk, Russia) nsv2107@mail.ru

Ekaterina A. Dyachkovskaya

Ammosov North-Eastern Federal University (Yakutsk, Russia) kachuuka@mail.ru

\title{
CULTURAL HERITAGE IN REGIONAL IDENTIFICATION STRATEGIES
}

\begin{abstract}
The article outlines a role that objects of cultural and natural heritage located in the today's Sakha Republic (Yakutia), Russia, play in a process of genesis of ethnic and cultural identity of Yakuts (endonym "Ssakhalar"), one of indigenous people from Turkic linguistic family settled in the region. The authors consider theoretical basis of mechanism for conversion of axiological and sense component of monuments of nature and the major objects of cultural landscape of an area into a resource for elaboration cultural and identification strategies of a region.

Key words: a people's ethnic and cultural identification, strategies of identification, a Russian region, mass consciousness, cultural and natural heritage, cultural identity, cultural values, day-to-day culture, traditional culture, ethnic and cultural consciousness, practices in social and cultural sphere, all-Russian projects, Yakuts, Sakha Republic (Yakutia).
\end{abstract}

УДК 069.014:281.96(571.14-25)

DOI: $10.32340 / 2414-9101-2019-3-14-19$

Е. А. Полякова, доктор исторических наук, доцент Алтайский государственный институт культуры, Барнаульский юридический институт Министерства внутренних дел Российской Федерации (Барнаул, Россия) elena2873@mail.ru

\section{МУЗЕИ СТАРООБРЯДЧЕСКОЙ КУЛЬТУРЫ КАК ИНСТРУМЕНТ ОБЕСПЕЧЕНИЯ НАЦИОНАЛЬНОЙ БЕЗОПАСНОСТИ РОССИИ (НА ПРИМЕРЕ МУЗЕЯ ИСТОРИИ СТАРООБРЯДЧЕСТВА СИБИРИ)}

Аннотация. Стратегия обеспечения национальной безопасности Российской Федерации в сфере культуры ориентирована на преодоление нравственного и культурного кризиса в государстве посредством возрождения традиционных духовно-нравственных ценностей. Механизм формирования национальной идентичности личности современного россиянина средствами традиционной культуры нашёл своё отражение в тексте «Основ государственной культурной политики» (2014 г.) России. Работа российских музеев как институтов социальной памяти составляет основу культурно-охранительной, культурно-просветительной и культурно-воспитательной деятельности в стране. Автор отмечает, что современная отечественная музейная сеть активно пополняется музеями старообрядческой культуры, ведущими работу по сохранению и актуализации исконных русских традиций и позиционирующих старообрядчество как духовное движение.

Ключевые слова: начиональная безопасность в сфере культуры, основы государственной культурной политики, традиционные ценности, старообрядчество, музей.

Второе десятилетие XXI века стало переломным этапом развития культурной политики России. Национальные приоритеты становятся базисом стратегии дальнейшего развития государства. Подтверждением начала обозначенных процессов является и «мюнхенскую речь» В. В. Путина 